\title{
A evolução artística e científica do origami: Um estudo teórico e prático sobre a prática e técnicas das dobraduras.
}

THE ARTISTIC AND SCIENTIFIC EVOLUTION OF THE ORIGAMI: A theoretical and practical study on the practice and techniques of folds.

Samanta Aline Teixeira ${ }^{1}$ Milton Koji Nakata ${ }^{2}$ 


\section{Resumo}

O presente artigo busca entender melhor como o origami foi inserido nas salas de aula e nas galerias de arte para depois se tornar um importante paradigma de inovação tecnológica, especialmente dentro da sustentabilidade. Para tal é feito uma revisão histórica baseada na trajetória de três artistas: Josef Albers, Ronald Resch e Lygia Clark. Investigando a evolução profissional de cada um, nota-se que muitos trabalhos profissionais e pesquisas multidisciplinares são inspirados nessas figuras modernas. Estudando aspectos apontados inicialmente pelos três artistas direta ou indiretamente, são analisados os componentes do origami como dobras-vale, dobras-montanha, crease pattern e o design do origami adaptado. Para complementação do estudo, é feito uma aplicação experimental de um protótipo de bolsa reaproveitando materiais usados; o objetivo é a comprovação prática das técnicas do origami levantadas no estudo, unindo o princípio das dobras com sustentabilidade.

Palavras-chave: origami, inovação, arte, sustentabilidade, crease pattern.

\section{Abstract}

This article aims to understand how origami was inserted in classrooms and art galleries and then become a major paradigm of technological innovation, especially within sustainability. For such study, a historical review is made based on the trajectory of three artists: Josef Albers, Ronald Resch and Lygia Clark. Investigating the professional evolution of each one, it is noticed that many professional works and multidisciplinary investigations are inspired in these modern figures. Studying aspects initially pointed out by the three artists directly or indirectly, the origami components are analyzed such as valley folds, mountain folds, crease pattern and adapted origami design. To complement the study, an experimental application of a bag prototype is done reusing used materials; the objective is the practical proof of origami techniques indicated by the study, joining the principle of folds with sustainability.

Keywords: origami, innovation, art, sustainability, crease pattern.

${ }^{1}$ laranjasat@gmail.com

2 milton@faac.com.br 


\section{Introdução}

O origami é a arte de dobrar papel, sem cortes ou cola. Apesar de sua origem ancestral na China e Japão, hoje o origami tem permeado uma série de inovações em milhares de áreas do conhecimento e tecnologia no mundo todo (LANG, 2009; LANG; IVERSON; YIM, 2011). Logo após a unificação da linguagem e difusão comunicacional no século XIX, o origami começou a se configurar como uma ferramenta inovadora tanto na concepção de artefatos quanto em pesquisas e ensinos multidisciplinares (LANG; HULL, 2005, p. 92). Em um primeiro momento, entre os anos 20 e 60, o processo criativo e científico do origami se construiu na experimentação artística tátil e na exploração matemática teórica com os professores Josef Albers (DEMAINE et al., 2015, p. 148), Ronald D. Resch (1992) e a artista Lygia Clark (ROLNIK, 2002, p. 181). No segundo momento, mais atual, o origami passa a ganhar autonomia e precisão técnica, tornando-se um modo vasto de linguagem que adentra múltiplos aspectos comunicativos e tecnológicos. Tal momento fez com que fosse possível elencar coerentemente os métodos artísticos e científicos:

Examinando-se mais de perto, ciência e origami não estão tão separados quanto você pensa, ou mesmo ciência e arte em geral. [...] Termos estéticos como "elegância" estão infiltrando-se na ciência; [...] Muitos cientistas, matemáticos, e tecnólogos são motivados pela ordem, beleza e elegância de suas áreas assim como qualquer pintor, escritor ou escultor. Pegue um cientista bem-sucedido em seu âmago, e você encontrará um artista perto da sua superfície. (LANG, 2009, p. ix, tradução nossa).

De fato, o potencial do origami enquanto intermediador de diferentes áreas do conhecimento é um dos aspectos que Johnson descreve dentro do processo criativo: "[...] somos mais bem-sucedidos ao conectar ideias do que ao protegê-las. [...] Boas ideias podem não querer ser livres, mas querem se conectar, se fundir, se recombinar. Querem se reinventar transpondo fronteiras conceituais." (JOHNSON, 2011, p. 21). As misturas entre as linguagens de arte e ciência são também indiciadas por Flusser (1985, p. 8): "[...] à medida que a ciência vai combatendo ideologias, vai ela própria absorvendo imagens e se ideologizando. [...] imaginação e conceituação que mutuamente se negam, vão mutuamente se reforçando.".

Argan afirma que a arte e o design possuem vitais características, especialmente dentro da nova realidade contemporânea em que estamos inseridos: construir projetos que visam questionar e solucionar a pobreza e o desperdício, assim como a insuficiência e a redundância de informações (ARGAN, 2005, p. 263). De acordo com Stewart (2007, p. 419), uma das possibilidades criativas que atende às questões colocadas por Argan são os estudos baseados em duas importantes premissas: a biomimética, tecnologia científica baseada nas estruturas e funções biológicas naturais, e o origami, arte ancestral japonesa que consiste em gerar diversos tipos de formas através de dobras. Com os desperdícios e excessos provenientes das ações humanas, veio a ameaça do fim dos recursos naturais do planeta e, em contrapartida, a busca por uma gestão geral mais sustentável. Stewart aponta que as estruturas dos seres vivos são um exemplo claro de espaço mínimo ocupado por excelência, mas como 
aplicar o dinamismo das estruturas biológicas naturais nos artefatos produzidos pelo ser humano? Greenberg et al. (2011, p. 217) acreditam que uma resposta para essa pergunta é o Orimimetics, quer dizer, a aplicação das dobras providas pelo origami para resolver problemas estruturais, especialmente àqueles que necessitam de um potencial cinemático para economia de espaço. Como Deleuze (1991) reflete, o origami encarado como estrutura remete tanto à sua forma dobrada como a desdobrada. A economia em materiais, processos e espaços, podendo se chamar de inovação tecnológica sustentável, diz respeito à elucidação de que os artefatos baseados no origami devem ser pensados nas suas formas compacta e expandida ao mesmo tempo, estando um intrínseco no outro:

A desdobra. Certamente, a desdobra não é o contrário da dobra nem sua elisão, mas a continuação ou a extensão do seu ato, a condição de sua manifestação. Quando a dobra deixa de ser representada para tornar-se 'método', operação, ato, a desdobra vem a ser o resultado do ato que se expressa precisamente dessa maneira. (DELEUZE, 1991, p. 60).

Se Greenberg et al. (2011) afirmam que o origami é uma ferramenta metodológica interessante para traduzir as estruturas biológicas naturais dentro das construções humanas, os estudos de Kobayashi, Kresling e Vincent (1998, p. 147) confirmam essa premissa ao buscarem uma simulação das folhas de árvore, especificamente as folhas da espécie faia, através do padrão de dobras Miura-Ori.

Figura 01: Compactação em dobras nas folhas da árvore Faia e no origami Miura-Ori.
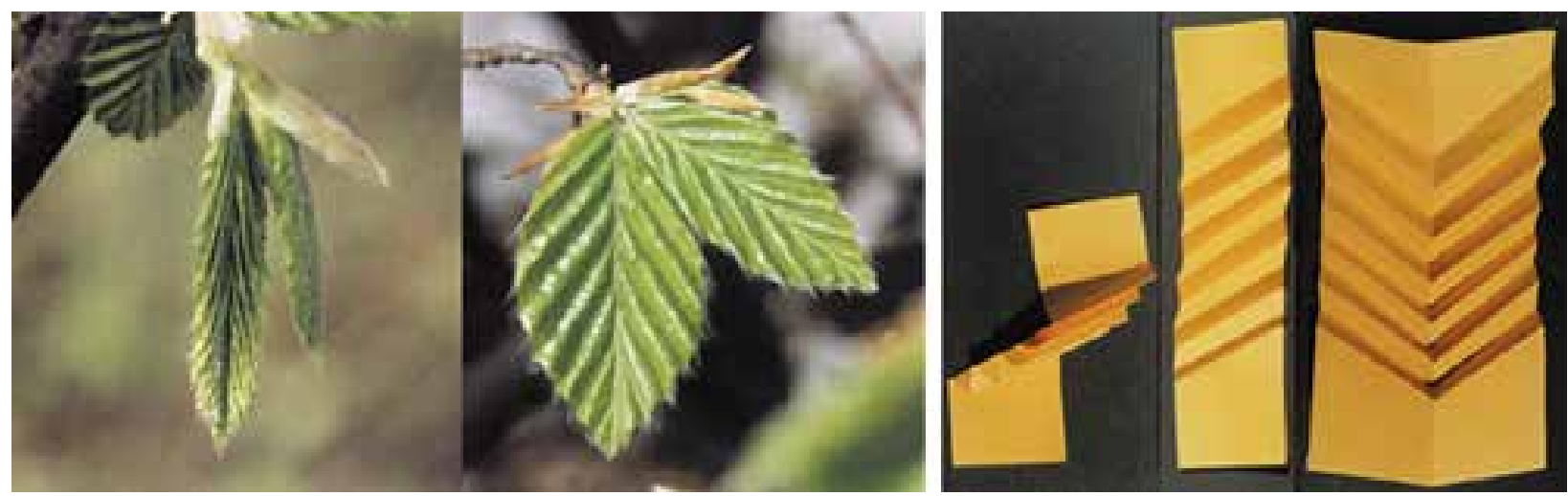

Fonte: KOBAYASHI; KRESLING; VINCENT, 1998, p. 148-153.

De acordo com Kobayashi, Kresling e Vincent (op. cit.), folhas de faia e de choupo-branco possuem padrões e mecanismos de dobramento simples e efetivos em economia de espaço, podendo servir de base para a concepção de estruturas como painéis solares e satélites ou membranas como tendas, roupas e outros tipos de revestimentos.

\section{Os primeiros estudos com origami e a apropriação contemporânea}

O origami possui uma gestão de modelagem que possibilita aplicações em diversos âmbitos, escalas e situações. Boa parte dessa ascensão técnica e metodo- 
lógica deve-se ao caráter naturalmente experimental e dinâmico que a prática das dobraduras conduz às pessoas. O professor Josef Albers foi um dos primeiros artistas a explorar o origami no período da arte moderna. Depois de lecionar em muitas escolas na Alemanha, Albers se fixou como aluno e posterior professor na escola de arte, design e arquitetura da Bauhaus. Quando a escola alemã fechou em 1933, Albers mudou-se para os Estados Unidos onde lecionou na Black Mountain College, e em Yale nos anos 50 (ADLER, 2004). Na área da arquitetura, o professor trabalhou com sobreposições de vidros e litografia. Mas foi o seu trabalho com o origami e kirigami (dobraduras que possuem dobras e recortes) que tornou Albers um dos grandes pioneiros na exploração artística e pedagógica com materiais e suas propriedades físicas (DEMAINE et al., 2015). A trajetória de Albers possuiu dois nortes importantes, seus trabalhos artísticos profissionais e sua pedagogia em sala de aula, ambos conectados através da prática das dobraduras:

Todos os artistas podem ser percebidos como os professores no sentido de que os seus trabalhos apresentam seus pensamentos e ideias para o público; isto é particularmente verdadeiro no caso de Albers, pois sua filosofia artística pessoal foi centrada em torno de convicções que eram aplicáveis tanto em âmbito da sala de aula quanto em uma galeria de arte. (ADLER, 2004, p. 2, tradução nossa).

Apesar das muitas mudanças de universidades, sempre estiveram presentes na conduta de Albers os ideais de exploração dos materiais como estabilidade, capacidade de carga, força exercida, padrões de dobras, e a forte crença de que os cursos de artes moldam as pessoas e sociedade. Inspirado pelos seus primeiros anos na vanguardista Bauhaus, Albers baseava sua metodologia artística e de ensino na experimentação tátil dos materiais, prática inédita e um tanto inusitada para a época: "[...] é importante reconhecer que Albers não se limitou a um único formato ou ideia. Ele experimentava constantemente com os meios tradicionais e contemporâneos, e criou um vasto corpo de trabalho diversificado" (ADLER, op. cit., p. 57, tradução nossa).

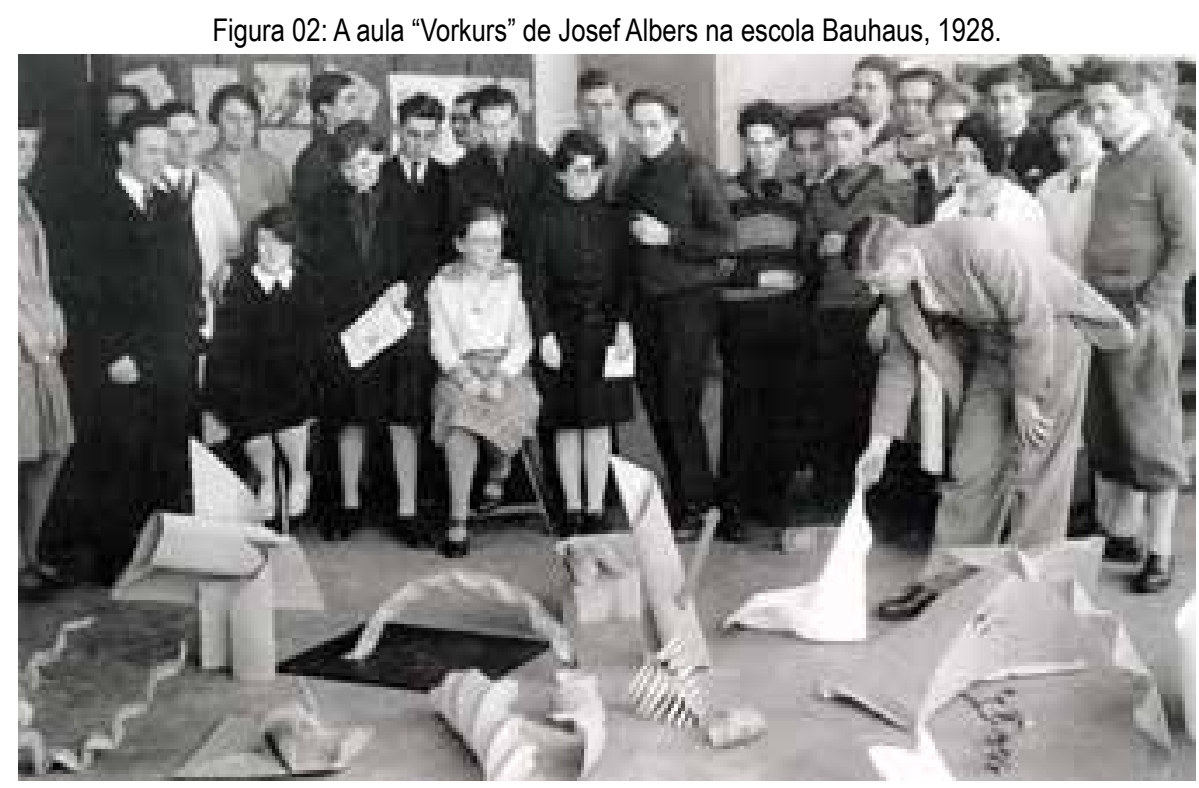

Fonte: Arquivos da Bauhaus. Disponível em: <https://www.flickr.com/photos/87334865@N08/albums/72157633016636829>. Acesso em: 06 Set. 2016. 
Figura 03: Estudos em origami de Josef Albers com alunos na escola Black Mountain College, 1946.
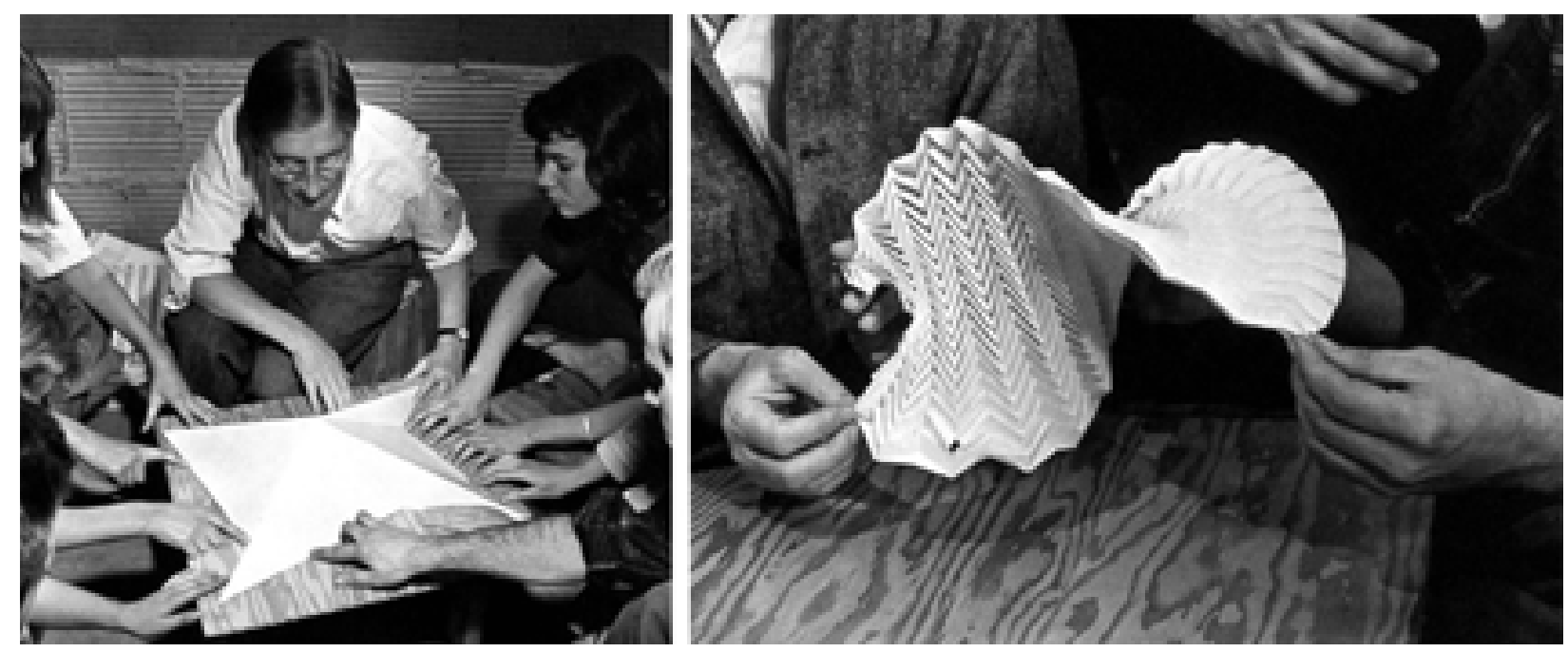

Fonte: Fundação The Josef and Anni Albers. Foto por Genevieve Naylor. Disponível em: <https://www.flickr.com/photos/87334865@N08/ albums/72157633016636829>. Acesso em: 06 Set. 2016.

Outro importante precursor dos estudos com origami foi o professor Ronald D. Resch (1992). Formado em artes na Universidade de lowa e, posteriormente, professor de ciências da computação na Universidade de Utah, Resch desenvolveu uma série de estudos práticos com o origami, fazendo surgir o ramo do Origami Tessellations nos anos 50 e 60 (GJERDE, 2008). Resch traz à tona as primeiras criações com o crease pattern (termo técnico do origami contemporâneo melhor explicado no próximo capítulo), além de evidenciar o potencial estético, matemático e cinemático que o mapeamento dos padrões de dobras carrega. Os diversos experimentos com dobras de Resch fizeram com que o artista obtivesse, ao longo do tempo, vasta experiência de aplicação diversificada do crease pattern, tornando-o uma referência constante de busca para soluções empresariais.

Figura 04: Padrões em dobras de Ron Resch.
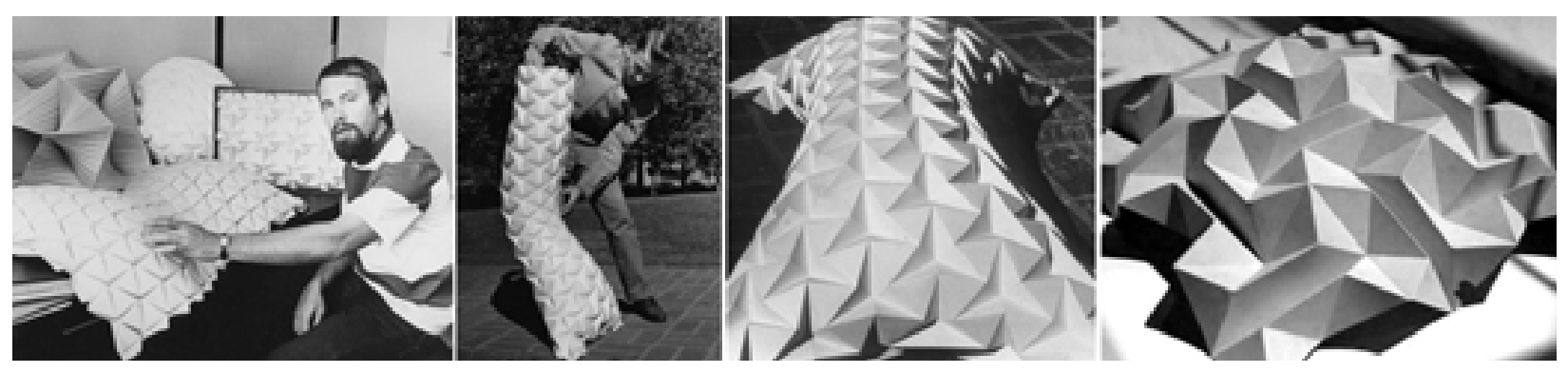

Fonte: RON Resh official website. [S.I.: s. n.], 2016. Disponível em: <http://www.ronresch.org/ronresch/>. Acesso em: 28 jun. 2016.

Enquanto pesquisador do origami, a trajetória de Resch fez com que concretizasse uma série de patentes, entre elas, o painel sanduíche, a pedido da multinacional The Royal Packaging Industries Van Leer, nos Países Baixos (RESCH, 1983). Ao demonstrar em suas aulas a importância das práticas, improvisos e insights do origami experimental, Resch inspira artistas e designers até hoje- um exemplo é o vaso de plantas Growth, do estúdio inglês Ayaskan. 
Figura 05: 0 vaso de plantas Growth, do estúdio Ayaskan.

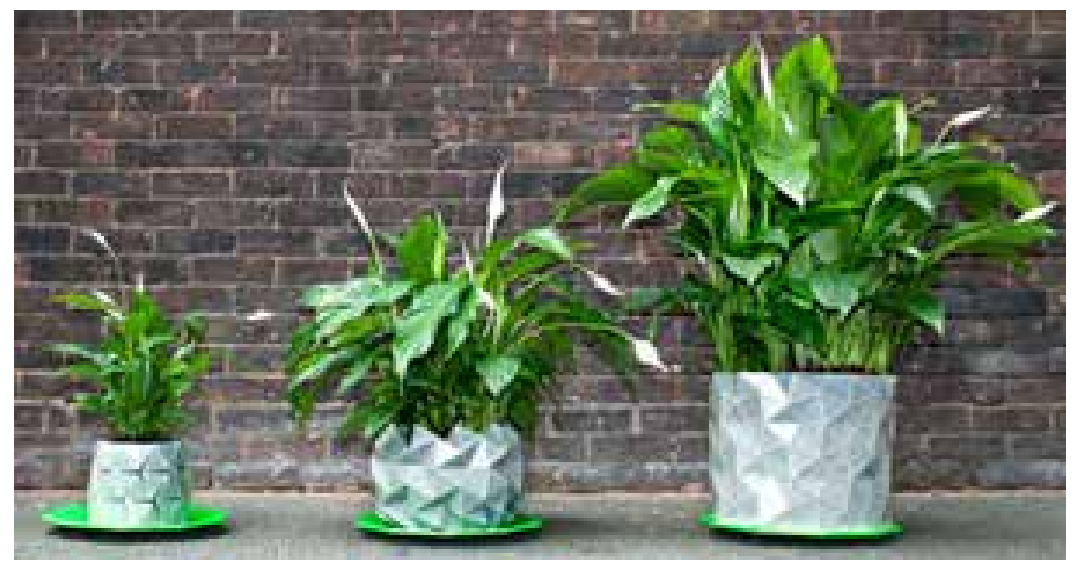

Fonte: AYASKAN studio. [S.I.: s. n.], 2016. Disponivel em: <http://ayaskan.com/work/growth/>. Acesso em: 31 ago. 2016.

A rigidez dos formatos dos vasos comuns não acompanha o crescimento contínuo das plantas, fazendo com que seja necessária uma troca contínua entre vasos pequenos e grandes. Uma prática comum, porém pouco ecológica. Utilizando o padrão de dobras de Ron Resch, as irmãs Bike e Begum Ayaskan criaram o vaso Growth com a intenção de reduzir o lixo criado pelos vasos inutilizados. Growth possui a estrutura em origami que se expande conforme as raízes vão crescendo, tornando possível a permanência do vaso durante todo o seu ciclo de vida da planta. Acomodando melhor o solo e raízes amplas em seu formato expandido, Growth é um projeto sustentável dinâmico e visualmente interessante e que só foi possível graças à dinâmica do crease pattern de Ron Resch.

Na mesma época de Resch, temos a artista Lygia Clark, no Brasil, que evidencia os primeiros estudos com origami de uma maneira particularmente diferente. Lygia Clark começou sua carreira artística em 1947, no Rio de Janeiro. Depois de frequentar estúdios em Paris, Clark fez parte do Grupo Frente e o Manifesto Neoconcreto no Brasil em 1954 e 1959 (BARACHINI, 2010). Assim como Resch e Albers, Clark demonstrou em sua carreira profissional um profundo interesse pelas propriedades dos materiais, as estruturas possíveis e seu potencial de mutação:

Marcada pela inquietude, Lygia Clark inicia seu percurso oferecendo grande contribuição ao projeto construtivo brasileiro [...]. Explora as possibilidades compositivas do plano, até que ele não mais a satisfaz, para, em seguida, ao abandonar a pintura, trabalhar com objetos tridimensionais, revolucionando, dessa forma, os princípios construtivos." (MEDEIROS, 2015, p. 54).

Lygia Clark foi uma das primeiras artistas brasileiras a atuar no campo do experimentalismo, juntamente com Hélio Oiticica, nos anos 60 e 70. (SPERLING, 2015, p. 18; MEDEIROS, op. cit., p. 36). Sua arte diferenciada girou em torno de três pontos principais: a geometria representacional, experiências corporais do público e o conceito do "não-objeto", criado pelo crítico Ferreira Gullar (SPERLING, op. cit.). O não-objeto, também conhecido como quase-corpo, se trata da superação da dualidade sujeito-objeto na arte representativa para adentrar no campo da vivência ativa. O exercício artístico de Oiticica e Clark estavam baseados nesse momento em uma nova noção de público: este tendo o papel não da interpretação de uma narrativa, 
mas no ser e vir-a-ser, no visualizar através do experimentar, na construção de percepções próprias dentro da relação ambiente e espectador (idem).

A obra de Clark paira pela virtualidade e a "proposição" no lugar da "proposta". Para Clark "a obra é o ato de fazê-la" (ibidem) e assim como Resch e Albers, sua revolução paradigmática estava no ato estético como campo de experiência (MEDEIROS, op. cit., p. 36). Lygia Clark possuiu várias fases de experimentações, mas foi na concepção da sua série mais famosa "Bichos", em 1960, que o origami ganha afinidade de linguagem como um todo.

Figura 06: "Bichos" de Lygia Clark.

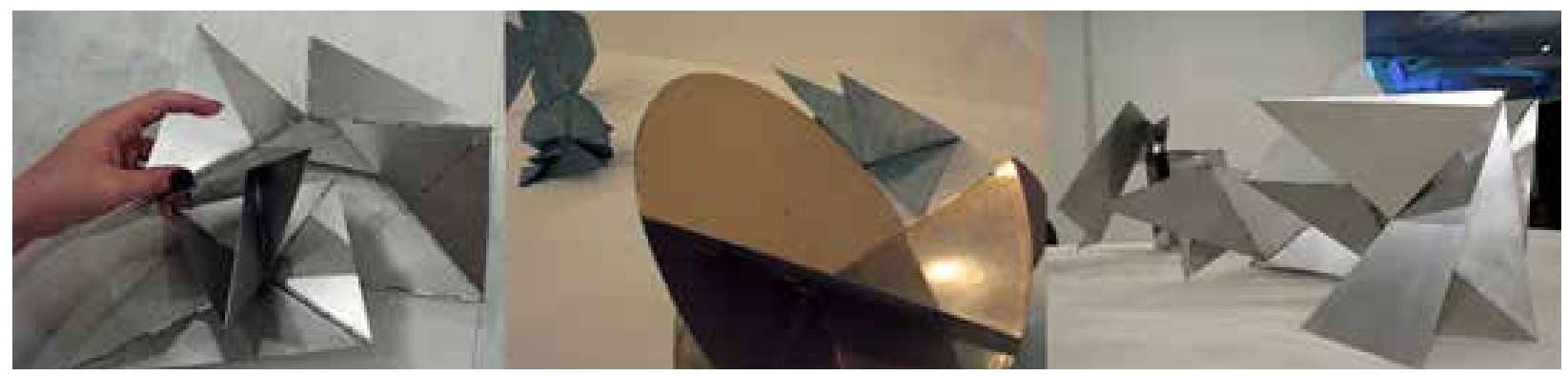

Fonte: Exposição Lygia Clark: Uma retrospectiva, 2012. Fotos tiradas pela autora.

"Bichos" surgiram na intenção de simular sistemas virtuais, abertos à manipulação (SPERLING, op. cit., p. 26-27). Constituindo-se como uma série de peças metálicas com dobradiças e planos deslizantes, "Bichos" podiam ser manipulados por todo e qualquer público que se encontrava no local da exposição. Caracterizadas pela modelagem com materiais rígidos como o metal, a proposição dessas peças segundo Medeiros (op. cit., p. 43) estava, além na mistura entre padrões rígidos e flexíveis: "podemos perceber como há um privilégio dessas transformações, da mutabilidade como característica intrínseca a eles, em detrimento da fixidez e da estabilidade das formas.". Para além da proposição principal, que era a participação ativa do espectador, as construções de Clark neste trabalho em particular são fundamentadas nos raciocínios das dobras. Mais ainda, por se tratar da transição entre o esquema de montagem em papel para o produto final em metal, os bichos de Lygia Clark foram um dos primeiros testes do que seria hoje a área mais recente e inovadora do origami aplicado a materiais rígidos: o chamado design do origami adaptado (MORGAN et al., 2016; FRANCIS et al., 2014).

Vários estudos baseados no origami aplicado em materiais rígidos estão sendo desenvolvidos, possuindo aplicações na medicina (KURIBAYASHI; YOU, 2003, 2009), na arquitetura (TACHI, 2011), móveis (MORGAN op. cit.), em telescópios espaciais (HYDE et al., 2002), painéis solares (ZIRBEL et al., 2013), entre outras novas apropriações das dobras. A prática do origami paira tanto sob a discussão e exploração estética, quanto em aplicações tecnológicas, ficando difícil identificar onde uma prática acaba e a outra começa- em verdade, muitas vezes elas estão intrínsecas entre si. A próxima figura ilustra uma escultura cinética desenvolvida na Brigham Young University, em Utah, Estados Unidos. 
Figura 07: Escultura cinética do museu de arte BYU.
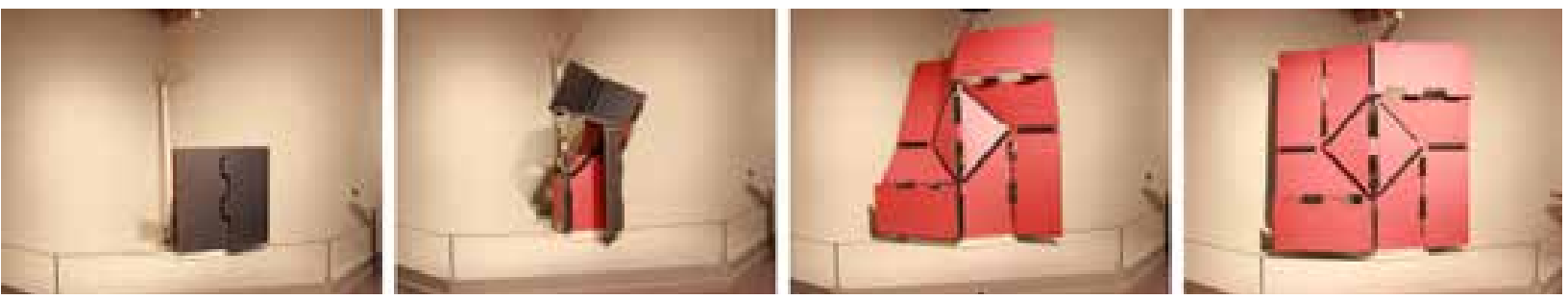

Fonte: MORGAN et al., 2014, p. 72.

A escultura foi exibida no museu de arte da universidade, sua criação é consequência da tentativa de adaptação de dobras em materiais rígidos. Com Lygia Clark a prática da dobra tanto no papel como no metal foi um meio para aproximar o sujeito e objeto em ambiente artístico. Seu trabalho, juntamente com outros artistas como Resch e Albers, construiu uma seriedade à estética do origami, além de servir como ponto-chave para que os matemáticos, designers e engenheiros continuassem a trajetória de estudos com o origami, dessa vez mais voltada para o funcionalismo tecnológico sustentável.

Outro trabalho de Clark que se aproxima do origami está na proposição subsequente da série "Bichos": "O dentro é o fora", de 1963, que se trata de uma continuação em metal da proposição "Caminhando", cuja experiência envolvia recortes da fita de Moebius em papel.

Figura 08: "O dentro é o fora" de Lygia Clark.

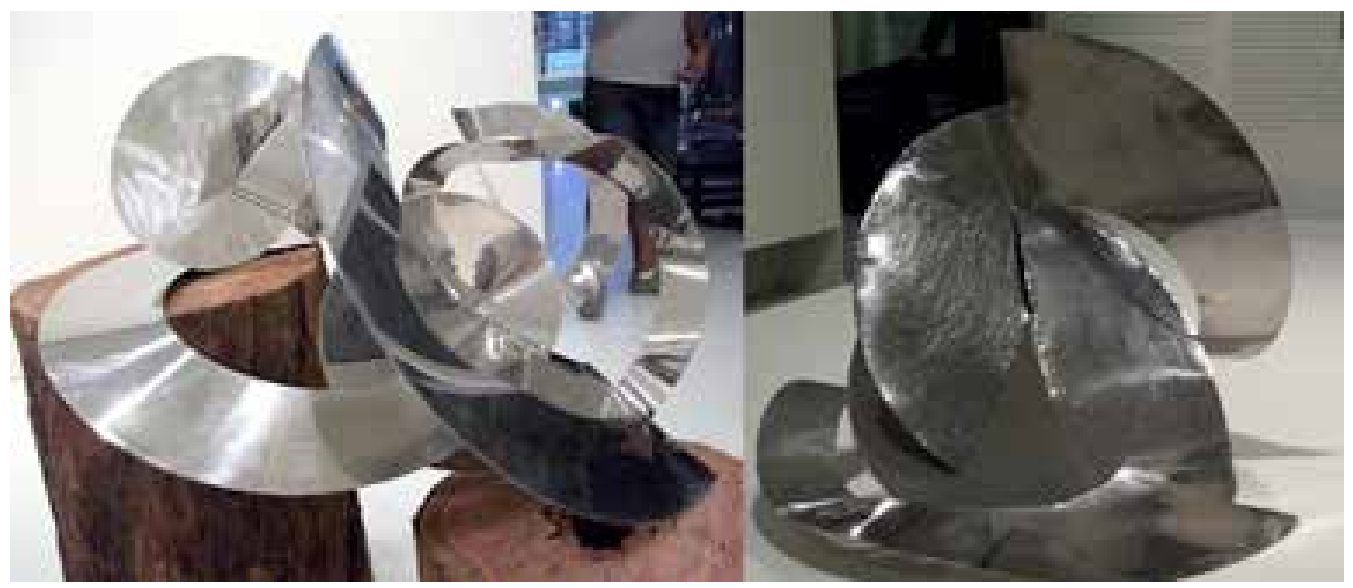

Fonte: Exposição Lygia Clark: Uma retrospectiva, 2012. Fotos tiradas pela autora.

O trabalho propunha uma experimentação entre o dentro que são os recortes da estrutura de metal e o fora percebido por quem manipula a forma plástica (BARACHINI, op. cit.). Nessa fase, a artista deixou os planos geométricos para trabalhar com formas mais arredondadas e orgânicas, assemelhando-se em muito com o origami em curvas, um dos estudos do professor Albers na Bauhaus. Inspirados pela aula "Vorkus" de Albers em 1927, o origami em curvas foi atualizado pelos cientistas computacionais Erik e Martin Demaine, do MIT - Instituto de Tecnologia de Massachusetts: 
Figura 09: 0 origami em curvas por Martin e Erik Demaine.
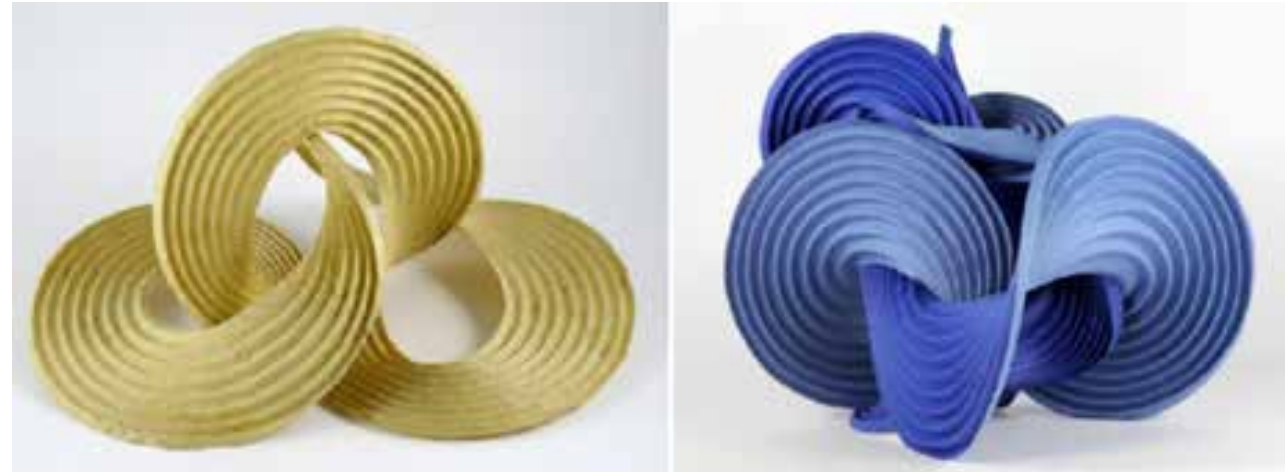

Fonte: DEMAINE et al., 2015.

Quando se pensa em origami, logo vêm à mente formas geométricas clássicas, como quadrados, triângulos e poliedros, aplicados mesmo em animais e plantas de papel. O trabalho dos pesquisadores Demaine, um resgate e atualização das aulas da antiga Bauhaus, mostram que as dobraduras também podem ser orgânicas, sem ângulos retos e maleáveis ao toque. Tal ramo do origami não é apenas fascinante visualmente, mas também alavanca novos processos de aplicação industrial na arquitetura e indústria automobilística, como o envelopamento de carros:

Figura 10: Projeto arquitetônico para espaço público e envelopamento de carro.
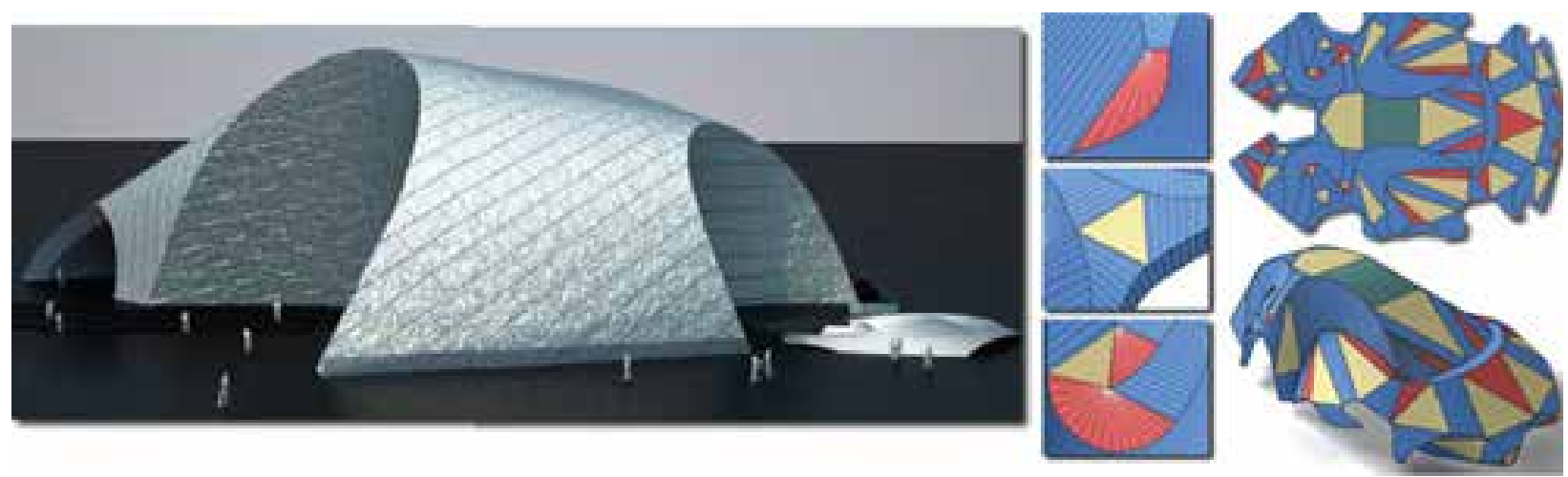

Fonte: KILLIAN et al., 2008.

Com as dobraduras em curvas, percebe-se que a dobra possui aspectos complexos que envolvem não apenas ângulos, linhas e planos, mas também formas complexas como elipses e fendas arredondadas, tornando o origami uma forma de modelagem mais complexa do que pensada superficialmente. As formas complexas que podem surgir de um simples pedaço de papel apenas com dobras remetem à dobra e matéria descrita por Deleuze (1991, p.17-18):

[...] um corpo tem um grau de dureza assim como um grau de fluidez, ou que ele é essencialmente elástico, sendo a força elástica dos corpos a expressão da força compressiva ativa que se exerce sobre a matéria. [...] Um corpo flexível e elástico tem ainda partes coerentes que formam uma dobra, de modo que elas não se separam em partes de partes, mas dividem-se até o infinito em dobras cada vez menores, dobras que sempre guardam certa coesão. 
De fato, com "Bichos" e "O dentro é o fora" de Clark, o origami é traduzido do "mole" do papel para a "dureza" do metal, preservando os mecanismos mutáveis que somente a dobra consegue potencializar, além de gesticular formas distintas como triângulos, quadrados e círculos com naturalidade lúdica. A referência ao origami não é explícita no trabalho de Clark como em Resch e Albers, mas sua técnica é claramente a mesma que as dobraduras japonesas, e essa premissa se torna clara ao se considerar as esquematizações de construção dos "Bichos" e sua obra anterior "Casulo", de 1958 (TEIXEIRA; MARAR; ROSSI, 2014, p. 104).

\section{Construções com dobras: possibilidades e técnicas}

Para entender melhor como o origami é fundamentado enquanto técnica em dobras, uma descrição é feita em cima de seus elementos e composições. De acordo com Hull (2002) a primeira característica fundamental do origami é que qualquer modelo em dobradura possui dobras-vale e dobras-montanha em suas configurações. O que torna um origami mais ou menos complexo é a combinação/interação entre suas dobras-vale e dobras-montanha. A segunda característica do origami é o crease pattern, que pode ser traduzido literalmente como padrão de vincos ou padrão de dobras. O crease pattern é um conjunto de linhas desenhadas ao longo do papel planificado. As linhas são a representação das dobras-vale e dobras-montanha. Alguns padrões possuem linhas de cor diferente para diferenciar as vales das montanhas e, assim, facilitar a montagem.

Figura 11: Dobra-vale em vermelho e dobra-montanha em azul.
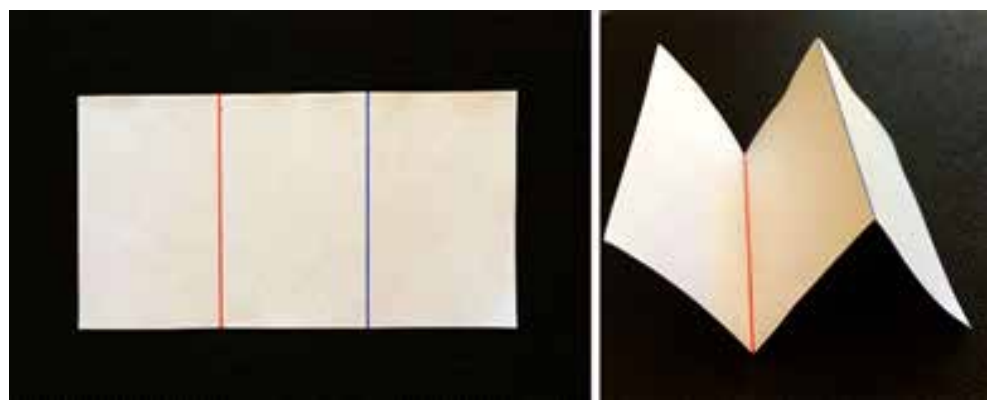

Fonte: elaborado pelos autores.

Figura 12: Padrão de dobras Shumakov e seu crease pattern.

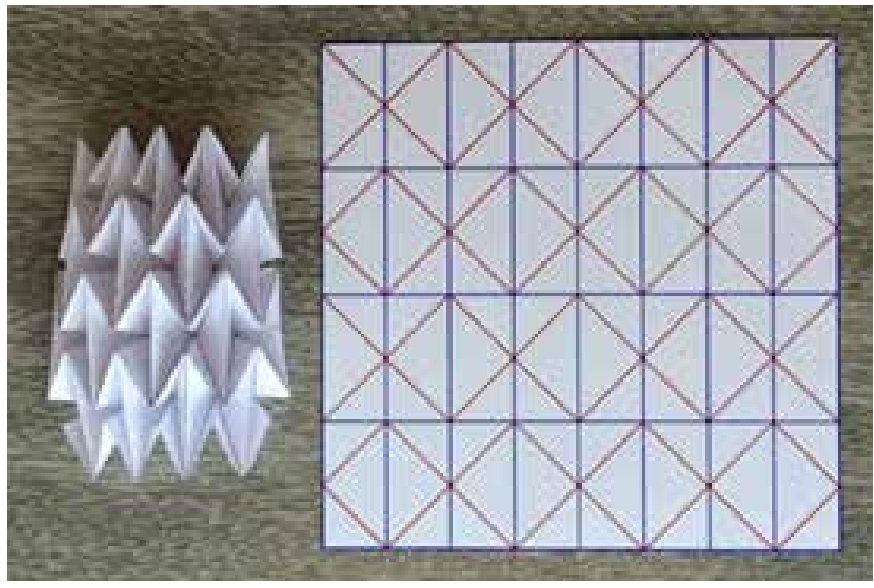

Fonte: elaborado pelos autores. 
Na figura 12 tem-se o padrão de dobras desenvolvido por Yuri Shumakov e Katrin Shumakov (2001), também conhecido como waterbomb. À direita tem-se o crease pattern do modelo, onde as linhas vermelhas são as dobras-vale e as linhas azuis são as dobras-montanha. À esquerda tem-se o origami final dobrado de acordo com o mapeamento do crease pattern. O que se torna claro ao dobrar um origami a partir de seus crease patterns é a visualização da construção do modelo como um todo, quer dizer, a transformação do plano 2D para o plano 3D e, consequentemente, da forma simples para a forma complexa. Devido a tal ato amplo e preciso de construção, o crease pattern passou a ser adotado como estratégia de design a partir de estudos como o Miura-Ori para materiais espaciais (MIURA, 1985) e o programa Ori-Revo (MITANI, 2009). Tais projetos foram elaborados objetivando diferentes inovações com a mesma ferramenta: o mapeamento de dobras em busca de formas específicas. $O$ próximo aspecto compositivo do origami diz respeito à adaptação de dobras em materiais rígidos: as dobras reais e as dobras substitutas, segundo Francis et al. (2014):

Figura 13: Dobra real em papel e dobras substitutas em materiais rígidos.

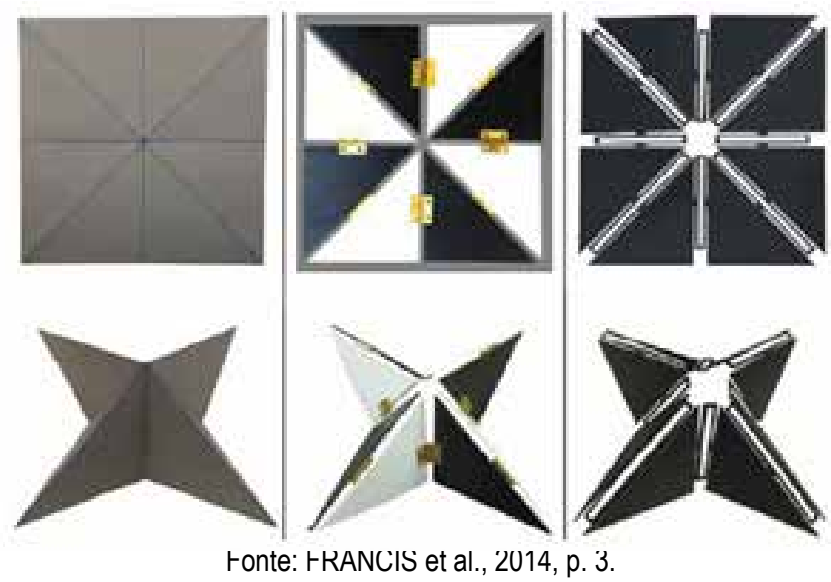

Na figura 13 se têm da esquerda para a direita as dobras reais de um origami no papel e dois tipos de adaptações das dobras em materiais rígidos. A primeira adaptação no meio utiliza dobradiças simples entre os planos triangulares. A segunda adaptação à direita possui dobradiças mais elaboradas, se aproximando mais do formato das dobras reais do que a primeira adaptação. Um exemplo aplicado de dobras substitutas pode ser observado na construção do telescópio Eyeglass:

Figura 14: O telescópio espacial Eyeglass, criado por Robert J. Lang.

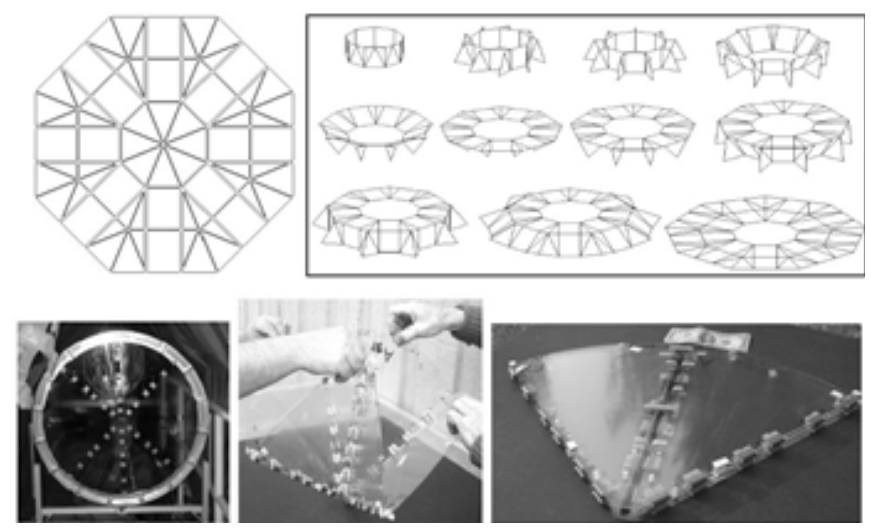

Fonte: HYDE et al., 2002, p. 35-36. 
O telescópio Eyeglass foi desenvolvido na Lawrence Livermore National Laboratory, em Livermore, Califórnia (HYDE et al., op. cit.). Na primeira linha da figura 14, da esquerda para a direita tem-se o crease pattern adaptado das lentes e a trajetória de dobragem do telescópio. Nas três fotos da segunda linha tem-se o registro de montagem em escala 1x1 do telescópio, feito com vidro (idem). Observando as fotos, percebe-se que as dobradiças possuem o mesmo tipo de adaptação para suas dobras como as demonstradas na figura 13.

O projeto surgiu com a intenção de deixar o telescópio pequeno para a viagem e grande para o destino, como Lang coloca (2009), ou seja, dobrado para entrar no foguete e desdobrado para quando chegar ao espaço. As dobras do telescópio possibilitam que sua forma desdobrada seja maior do que telescópios comuns; dessa maneira, o Eyeglass consegue capturar imagens de planetas e estrelas com maior resolução e detalhes. Na tentativa de entender melhor o origami aplicado em materiais rígidos, Morgan et al. (2016) reuniram as diferentes técnicas de dobras reais para dobras substitutas desenvolvidas por outros pesquisadores do origami contemporâneo, como mostra a figura abaixo:

Figura 15: As diferentes técnicas de dobragem em materiais rígidos

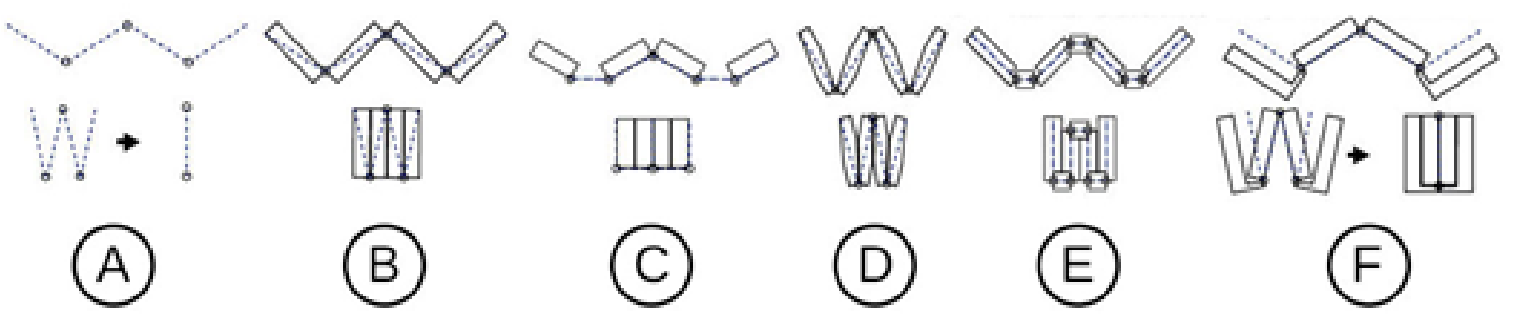

Fonte: adaptado de MORGAN et al., 2016, p. 71.

Na figura acima, cada técnica envolve uma estratégia diferente de adaptação da dobra real para a dobra substituta. Em (A), o modelo ilustrado é de um origami original, ou seja, é a planificação da dobra real e seu comportamento cinemático com espessura zero. Em (B), tem-se o método de deslocamento dos eixos rotacionais do centro da espessura do material para suas bordas superiores ou inferiores, técnica desenvolvida por Tachi (2011). Em (C), tem-se o método das dobras em membrana, que é a colocação de planos espessos sob uma membrana flexível, técnica desenvolvida por Zirbel et al. (2013). Em (D), tem-se o método de painéis afunilados, que é o desbaste das faces espessas para preservar a cinemática do modelo, técnica desenvolvida por Tachi (2011). Em (E), tem-se o método de deslocamento dos vincos das dobras, semelhante à técnica das dobras em membrana, mas que precisa de um material rígido nas lacunas entre os painéis, técnica desenvolvida por Abel et al. (2015). $\mathrm{Em}(\mathrm{F})$, tem-se o método de deslocamento de painéis (conhecido como OPT - Offset Panel Technique): trata-se do deslocamento de cada painel a partir de um plano de encaixe que estende os eixos rotacionais de volta para o plano de união desses painéis, técnica desenvolvida por Edmondson et al. (2014).

Todas as técnicas descritas se referem a métodos de aplicação do origami em materiais que são rígidos e/ou possuem densidade maior do que o papel. Devido a essas características, tanto o crease pattern quanto o modo de construção requerem que o origami adaptado seja um pouco diferente do original. 


\section{Estudo prático: concepção de bolsa-origami}

Em busca de uma comprovação prática dos estudos do origami adaptado em diferentes materiais, esta etapa da investigação diz respeito ao processo de concepção de um protótipo que envolva o origami. A escolha foi de uma bolsa-origami reaproveitada de materiais usados com as premissas de sustentabilidade indiciadas por Kazazian (2005). Diante das muitas dificuldades em lidar com o lixo no mundo atualmente, surge a questão de como reaproveitar roupas usadas de maneira que elas sejam novamente aquisições de interesse do público consumidor. Apesar da importância cada vez mais ascendente da sustentabilidade, poucos estudos acadêmicos se focam no reaproveitamento de roupas manufaturadas: algumas tecnologias patenteadas buscam o reaproveitamento de água na lavagem de roupas (DE SOUZA, 2000), na secagem de roupas (SUN; WANG; LI; 2013) e a remodelagem industrial de roupas usadas para confecção de novas fibras sintéticas (NAKAJIMA, 1991). O estudo prático busca a contribuição experimental do crease pattern através da concepção de alguma peça de roupa descartada. Muitos objetos foram pensados para esta etapa, escolheu-se o produto bolsa por conta de ser um acessório de moda com função comum, direta e clara. Sua utilidade em guardar coisas permite que crease patterns menos mutáveis que outros possam ser aplicados de maneira a apropriar a estética do origami ao mesmo tempo em que se reaproveitam os materiais usados. A concepção da bolsa-origami é feita considerando duas premissas: 1- o crease pattern; 2- o material e método.

\section{1. Crease pattern}

A aplicação do crease pattern para o projeto da bolsa surgiu com duas intenções: 1- adotar a linguagem do origami em busca de revalorizar materiais que seriam descartados; 2- criar uma estrutura dinâmica para modelar o conteúdo interno da bolsa de maneira diferenciada, possibilitando o que se pode chamar de "desenhos visuais", estes se modificando conforme a diferença de formas dos objetos guardados na bolsa. Alguns crease patterns foram testados, como o Miura-Ori, de Koryo Miura (1985), e o waterbomb, de Yuri Shumakov e Katrin Shumakov (2001). Escolheu-se o crease pattern de Ron Resch devido a sua forma estrutural mais consistente e não tão mutável quanto os anteriores citados.

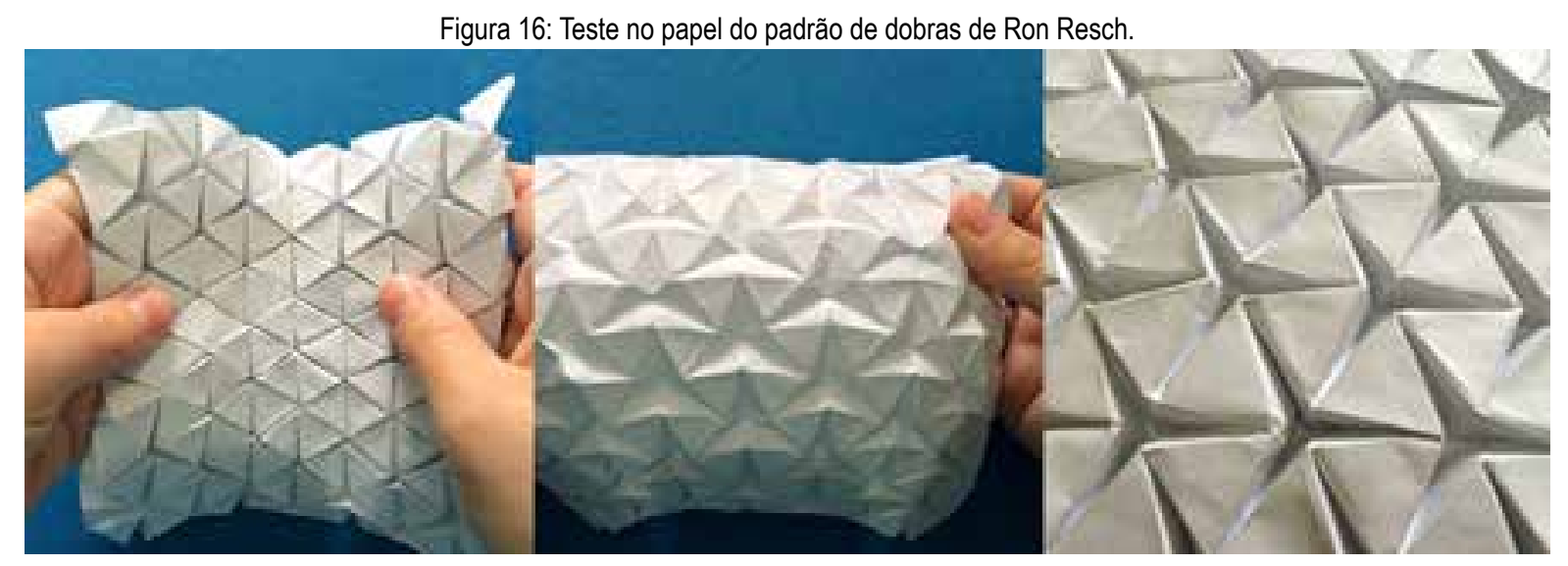

Fonte: Elaborado pelos autores. 


\section{2. Material e método}

Em busca da sustentabilidade através da reapropriação de materiais usados, inicialmente foi escolhido para o protótipo uma blusa velha como matéria-prima principal. Porém, para que o padrão de dobras fique muito bem desenhado sob o tecido, que é maleável e flexível, é necessário que exista algum tipo de estrutura interna rígida que possua o desenho do crease pattern. A escolha do material reaproveitado para essa estrutura foi papelão de embalagem de comida. Com a evolução da construção do protótipo, posteriormente foram reutilizados também papelões de caixas e capas de revistas velhas.

Figura 17: Materiais reaproveitados: blusa usada e embalagem de comida.

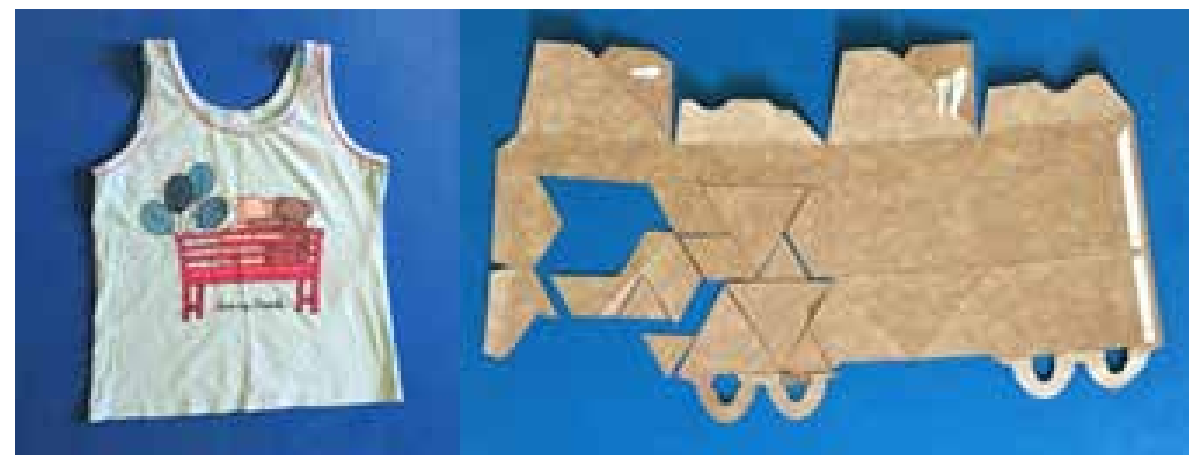

Fonte: Elaborado pelos autores.

Para o desenvolvimento da bolsa-origami, escolheu-se o método das dobras em membrana, elaborada por Zirbel et al. (2013), que se trata da colocação de faces rígidas (as figuras geométricas das embalagens e papelão) sob uma membrana flexível (o tecido). Nesta etapa percebe-se a importância do conhecimento e elenco de métodos de aplicação do origami adaptado por Morgan et al. (2016, p. 71). Considera-se a fase a mais importante, pois é nela que se verifica a aplicação da técnica de modo experimental e que se esclarece o nível de alcance metodológico do origami adaptado para o produto. A seguir, algumas figuras do processo de montagem:

Figura 18: Construção, recorte e colagem dos padrões de dobra no lado avesso da blusa.
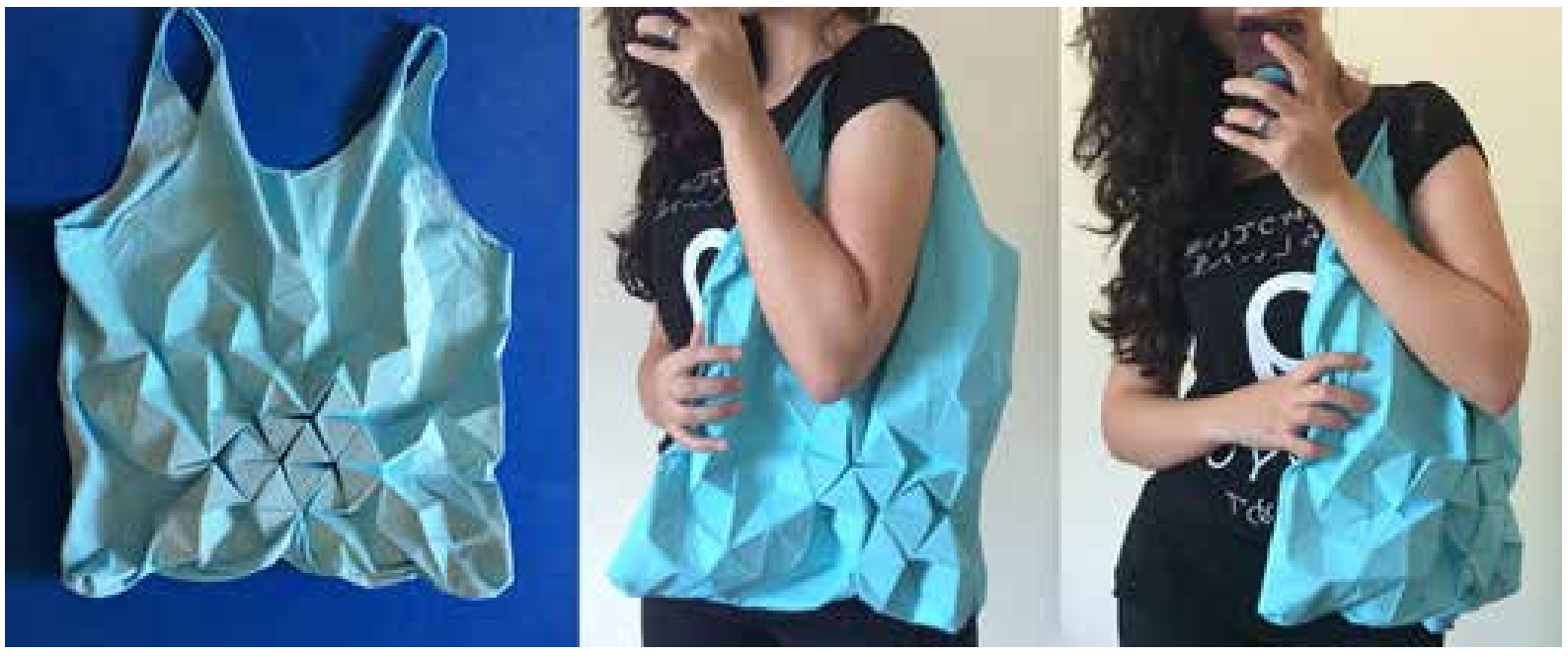

Fonte: Elaborado pelos autores. 
Após acabado o protótipo final da bolsa, alguns aspectos são levantados. Os pontos positivos foram os seguintes: 1) É uma bolsa de estrutura externa simples, não possui costura ou formato inicial complexo. Dessa maneira, blusas, camisetas e vestidos usados são facilmente reapropriados por este tipo de metodologia desenvolvida; 2) Sua aparência visual é diferenciada. O formato direto e prático facilita o uso no dia-a-dia; 3) O conteúdo interno da bolsa tanto participa da formação externa das dobras quanto é preservado devido à modelagem dinâmica e adaptativa do crease pattern; 4) Os materiais usados na bolsa foram reutilizados de maneira a serem inseridos no mercado de produtos uma vez mais; 5) O protótipo da bolsa é uma comprovação prática da técnica do design adaptado do origami, compondo mais um entre diversos outros projetos de inovação do origami contemporâneo.

Os pontos negativos foram os seguintes: 1) A complexidade da viabilização industrial deste produto está na estrutura interna elaborada para o crease pattern. É uma estrutura complexa e específica que precisa de mais estudos focados para a produção manufaturada; 2) Não é todo tipo de roupa usada que é viável para este tipo de reaproveitamento. Calças e shorts, por exemplo, estariam fora da proposta, embora não haja impedimentos para estudos futuros considerando estes e outros tipos de confecção; 3) A escolha dos materiais levantou um questionamento pensado após a execução do protótipo: surgindo a necessidade de se lavar a bolsa, os papelões internos inviabilizam a integridade estrutural do produto. Nesse questionamento, outro material foi pensado para substituição do papelão: o tetra brik, cuja estrutura é composta por quatro camadas de plástico, uma de papel e uma de alumínio. $O$ tetra brik pode ser interessante para a elaboração do crease pattern, pois possui o mesmo efeito estrutural rígido e é impermeável à água, além de ser amplamente utilizado em embalagens de perecíveis e de difícil reciclagem.

\section{Discussão dos resultados}

Os recentes estudos aplicados do origami adaptado em diferentes materiais vão além do funcionalismo e inovação tecnológica: eles são uma precisa reflexão e tradução da importância das lacunas nos materiais e estruturas. Sabe-se através de Flusser (2007, p. 208-209) e Azevedo (1994, p. 75) que o origami, assim como outros tipos de arte que nasceram no Japão e região, carrega o "fazer" oriental, dizendo respeito a transcendências que ainda hoje o ocidente busca descobrir e alcançar. O mundo ocidental, influenciado pelos Estados Unidos e Europa, se apropria do preenchimento de espaços vazios com o máximo de informações possíveis. Já o mundo oriental considera o próprio vazio dos espaços um potencial de linguagem inata: "No Oriente, além da palavra, o próprio silêncio passou de pai para filho, e, no que tange à questão da tradição, o silêncio é compreendido como informação." (AZEVEDO, op. cit.). A estética do silêncio, ou do vazio que preenche, pode ser observada no filme "A casa vazia", de Kim Ki-duk (2004) e nas reflexões do filósofo chinês Lao-Tsé (1991, p. 45): "O oleiro faz um vaso, manipulando a argila, mas é o oco do vaso que lhe dá utilidade. [...] Assim são as coisas físicas, que parecem ser o principal, mas seu valor está no metafísico". A descrição de Tsé, em primeiro instante, pode parecer que gira em torno da subjetividade e do idealismo irreal. Porém, se observar com cuidado o seu conteúdo, nota-se que a descrição dos espaços vazios que possuem função, a exemplo do vaso ou 
moinho de vento, se tratam de um repensamento dos artefatos sob uma perspectiva muito mais atenta e ampla. A reunião de técnicas do origami adaptado por Morgan et al. (2016), figura 15, nada mais são do que diversas maneiras de apropriar o vazio gerado pelo vinco, o ato de marcar o papel com as dobras. Se o origami consegue hoje se imiscuir sob diversas (para não dizer todas) áreas do conhecimento e tecnologias emergentes, sem dúvida é devido ao seu caráter de adaptação, mutabilidade, e modulação inerentes. No estudo teórico foi visto que depois da nova independência autoral do origami adquirida pelo origamista Akira Yoshizawa (LANG, 2009), estudiosos como Josef Albers e Ronald Resch se apropriaram das dobraduras de maneira mais experimental, pedagógica e científica, revolucionando a maneira como os artistas, designers, engenheiros e cientistas encaram a arte de dobrar papel. No Brasil, Lygia Clark interpretou o ato da dobra à sua maneira, trazendo questionamentos importantes como o novo papel do público e dos objetos de arte em conjunto com a exploração dos materiais e estruturas. No estudo prático foi visto que é possível aplicar de maneira precisa uma das técnicas reunidas por Morgan et al. (op. cit.) com relação ao origami adaptado em diferentes materiais, o que proporcionou um protótipo de bolsa sustentável e dinâmico, além de salientar a importância do conhecimento sobre o princípio do crease pattern como elemento essencial do origami contemporâneo. Por fim, a presente pesquisa buscou elucidar os princípios criativos do origami sob um viés teórico e prático. Para tal, foram analisadas as trajetórias históricas das práticas com as dobras dentro das salas de aula e das galerias de artes com Albers, Resch e Clark. Em diferentes escalas e apropriações particulares, os três artistas trouxeram à tona explorações com as dobras em âmbito do ensino experimental, arte mutável e inovação em design. No estudo prático, viu-se que as técnicas do origami adaptado são importantes para entender e aplicar melhor as dobras em materiais diferentes do papel e que o princípio do crease pattern é uma forma de raciocínio prático tangível tanto ao cientista quanto ao artista.

\section{Considerações finais}

O origami é o principal componente de referência para diversos tipos de projetos em pesquisa no mundo todo. Apesar de sua trajetória científica possuir pelo menos 20 anos de experiência em países como Estados Unidos, Japão, China, Alemanha e Reino Unido, no Brasil é ainda um assunto timidamente abordado no âmbito acadêmico. Uma das grandes dificuldades de estudos com o origami hoje é entender e filtrar todo o material densamente teórico do estrangeiro para nosso país. Dado que o origami já não é um assunto tão novo no exterior, a complexidade de suas teorias está em modo avançado, já pré-conhecido pela maioria da comunidade científica mundial. Os artigos científicos de origami passaram há algum tempo da esfera de descobertas de formas dobradas para descobertas de algoritmos de origamis digitais, automações tecnológicas de dobras mecânicas, fórmulas geométricas desenvolvidas a partir de tantas outras. Ao passo que em solo brasileiro, ainda estamos na escala das primeiras descobertas e registros em língua nacional dos estudos científicos com origami. Outra dificuldade encontrada, consequência desta primeira, é o acesso restrito ao material teórico. As agências de fomento em pesquisa no Brasil focam o investimento na área de ciências da saúde, deixando em segundo e terceiro plano 
a área das engenharias, design e artes. Áreas estas que são fundamentais para quem estuda sobre o origami projetual, pois é onde estão as pesquisas que se focam no desenvolvimento tecnológico de novos equipamentos, novos maquinários, novas formas de gerar produtos e serviços, etc. Nosso meio de ter acesso aos artigos focados no origami enquanto tecnologia aplicável foi abordando os autores diretamente por e-mail.

Contudo, da dificuldade surge também a possibilidade, por conta do assunto ser novo no país, as alternativas de abordagens, análises e experimentações são abrangentes. Se de um lado, há uma freqüente necessidade de referenciais brasileiros para se pautar, por outro lado há sempre um modo novo de analisar e aplicar o origami contemporâneo.

Com relação aos resultados finais deste artigo, vale apontar que a principal fonte do processo criativo foi a constante prática direta com origamis estudados nos artigos. Quando se trata da experiência de uma linguagem, não basta apenas ler sobre o assunto, é necessário desenvolver uma série de práticas experimentais para se entender o modus operandi de forma mais aprofundada. A bolsa-origami surgiu de duas necessidades, testar as técnicas de dobras estudadas e desenvolver um projeto de produto sustentável. Este último aspecto é de fundamental importância para os designers/artistas hoje, uma vez que o fim dos recursos naturais é uma ameaça palpável, resultado de um capitalismo que sempre visou a quantidade em curto prazo no lugar da qualidade em longo prazo. Com a série de estudos voltados para o origami atualmente, a diversidade de aplicações das dobraduras é ainda maior se considerar apenas os projetos voltados para o mercado, ficando mais difícil saber as escolhas de um projeto inovador do que as opções intrínsecas a ele.

Considerando as dificuldades e possibilidades, o presente artigo buscou uma contribuição no sentido de solidificar melhor a pesquisa e a prática profissional do origami, apontando alguns pilares de conhecimentos adquiridos atualmente com as dobraduras japonesas para que, com estes pontos iniciais, façam-se muitas outras pesquisas bibliográficas e experimentais com o origami em solo nacional. Os próximos desafios a serem explorados estão na aproximação do origami com as novas tecnologias, como as impressoras 3D, as máquinas de corte a laser, a aplicação de dobras em diferentes materiais (especialmente os metamateriais, a mais nova área da tecnologia transdisciplinar) e a conexão com outras áreas teóricas e experimentais, buscando mais projetos que possuam maior grau de inovação, sustentabilidade e compromisso social.

\section{REFERÊNCIAS BIBLIOGRÁFICAS}

ABEL, Z. et al. Rigid Origami Vertices: Conditions and Forcing Sets. Cambridge University Press, Cambridge, v. 7, n. 1, p. 171-184, 2015.

ADLER, E. D. A New Unity! The art and pedagogy of Josef Albers. 2004. Dissertação (Mestrado em Artes) - University of Maryland, College Park, 2004.

ARGAN, G. C. História da arte como história da cidade (trad. Pier Luigi Cabra). 5. ed. São Paulo: Martins Fontes, 2005. 
AZEVEDO, W. Os signos do design. São Paulo: Global, Col. Contato Imediato, 1994.

AYASKAN studio. [S.l.: s. n.], 2016. Disponível em: <http://ayaskan.com/work/growth/>. Acesso em: 31 ago. 2016.

BARACHINI, T. Lygia Clark e seus objetos de flexibilidade implícita. In: I CSO Congresso Internacional Criadores Sobre outras Obras (ed. João Paulo Queiroz), 2010, Lisboa. Anais eletrônicos... Lisboa: FBAUL, 2010. Disponível em: <http://cso.fba.ul.pt/ atas.htm>. Acesso em: 07 set. 2016.

DELEUZE, G. A Dobra: Leibniz e o barroco (trad. Luiz B. T. Orlandi). Campinas: Papirus, 1991.

DEMAINE, E. D. et al. A review on curved creases in art, design and mathematics. Symmetry: Culture and Science, Hungria, v. 26, n. 2, p. 145-161, jul. 2015.

DE SOUZA, F. F. Clothes washing machine water reutilisation technique doubles efficiency, through recycling of the rinsing water to carry out the next wash. BR9901898-A, 14 jun. 1999, 07 nov. 2000.

EDMONDSON, B. J. et al. An Offset Panel Technique for Thick Rigidily Foldable Origami. In: Proceedings of ASME 2014 International Design Engineering Technical Conferences \& Computers and Information in Engineering Conference. Conferência... Buffalo: The American Society of Mechanical Engineers, 2014. (38, v. 5B). ISBN $978-$ 0-7918-4637-7.

CASA vazia. Direção: Kim Ki-duk. Intérpretes: Seung-yeon Lee; Hyun-kyoon Lee; Hyuk-ho Kwon. Coreia do Sul: Kim Ki-Duk Film; Cineclick Asia, 2004. 1 DVD (88 min.) son., color.

EXPOSIÇÃO Lygia Clark: Uma retrospectiva. São Paulo: Itaú Cultural, 2012.

FLUSSER, V. Filosofia da caixa preta: Ensaios para uma futura filosofia da fotografia. São Paulo: Hucitec, 1985.

O mundo codificado: Por uma filosofia do design e da comunicação (trad. Raquel Abi-Sâmara). São Paulo: Cosac Naify, 2007.

FRANCIS, K. C. et al. From crease pattern to product: considerations to engineering origami-adapted designs. In: Proceedings of ASME 2014 International Design Engineering Technical Conferences \& Computers and Information in Engineering Conference. Conferência... Buffalo: The American Society of Mechanical Engineers, 2014. (38, v. 5B), p. 1 - 15. ISBN: 978-0-7918-4637-7. 
GJERDE, E. Origami Tessellations: Awe-Inspiring Geometric Designs. Massachusetts: A K Peters, 2008.

GREENBERG, H. C. et al. Identifying links between origami and compliant mechanisms. Mechanical Sciences, v. 2, p. 217-225, dez. 2011. DOI: 10.5194/ms-2-217-2011.

HULL, T. The combinatorics of flat folds: a survey. In: Origami 3: Third International Meeting of Origami Science, Mathematics, and Education. Encontro Internacional... Massachusetts: A K Peters, 2002.

HYDE, R. et al. Eyeglass: A Very Large Aperture Diffractive Space Telescope. In: Proceedings of SPIE Highly Innovative Space Telescope Concepts (Ed. Howard A. MacEwen). Conferência... Washington: SPIE The International Society for Optics and Photonics, 2002. (v. 4849), p. 28-39. DOI: 10.1117/12.460420.

JOHNSON, S. De onde vêm as boas ideias (trad. Maria Luiza X. de A. Borges). Rio de Janeiro: Jorge Zahar Ed., 2011.

KAZAZIAN, T. Haverá a idade das coisas leves: design e desenvolvimento sustentável (trad. Eric Roland Rene Heneault). São Paulo: SENAC, 2005.

KOBAYASHI, H. KRESLING, B. VINCENT, J. F. V. The geometry of unfolding tree leaves. The Royal Society, Londres, v. 265, n. 1391, p. 147-198, 1998.

KURIBAYASHI, K. YOU, Z. A novel origami stent. In: Summer Bioengineering Conference, 2003, Key Biscayne. Conferência... Florida: Tulane University, 2003.

Expandable tubes with negative poisson's ratio and their application in medicine. In: Origami 4 - Fourth International Meeting of Origami Science, Mathematics, and Education (org. Robert Lang), 2006, Pasadena. Encontro Internacional... Massachusetts: A K Peters, 2009.

KILLIAN, M. et al. Developable Surfaces with Curved Creases. In: RFR and Waagner-Biro Stahlbau AG. Advances in Architectural Geometry. Simpósio... Viena: Vienna University of Technology, 2008. (1, v. 1), p. 33-36. ISBN 978-0-7918-4637-7.

LANG, R. J. Origami 4: Fourth International Meeting of Origami Science, Mathematics, and Education. Massachusetts: A K Peters, 2009.

LANG, R. J. HULL, T. Origami design secrets: mathematical methods for an ancient art. Mathematical Intelligencer, Estados Unidos, v. 27, n. 2, p. 92-95, 2005.

LANG, R. J. IVERSON, P. W. YIM, M. Origami 5: Fifth International Meeting of Origami Science, Mathematics, and Education. Massachusetts: A K Peters, 2011. 
MEDEIROS, I. A Relação entre corpo e subjetividade na obra de Lygia Clark. Concinnitas, Rio de Janeiro, v. 1, n. 26, p. 36-58, jul. 2015. ISSN: 1981-9897.

MITANI, J. A Design Method for 3D Origami Based on Rotational Sweep. Computer-Aided Design and Applications, Estados Unidos, v. 6, n. 1, p. 69-79, 2009.

MIURA, K. Method of Packaging and Deployment of Large Membranes in Space. In: 31 st Congress of the International Astronautical Federation, 1980, Tóquio. Congresso... Japão: The Institute of Space and Astronautical Science report, dez. 1985 (618). ISSN: 02856808.

MORGAN, M. R. et al. Towards developing product applications of thick origami using the offset panel technique. Mechanical Sciences, Alemanha, v. 7, n. 1, p. 69-77, mar. 2016. ISSN: 2191-9151.

NAKAJIMA, Y. M. Moulding material from synthetic fibre scrap - e.g. reduced and opened-up clothing pieces are mixed with thermoplastic plus additives. JP91052499-B, 13 mai. 1983, 12 ago. 1991.

RESCH, R. D. Construction-element. US4397902 A, 27 dez. 1977, 9 ago. 1983.

ROLNIK, S. Molda-se uma alma contemporânea: o vazio-pleno de Lygia Clark. In: LEÃO, L. (Org.). Interlab: Labirintos do pensamento contemporâneo. São Paulo: Iluminuras, 2002.

RON Resh official website. [S.l.: s. n.], 2016. Disponível em: <http://www.ronresch. org/ronresch/>. Acesso em: 28 jun. 2016.

SHUMAKOV, K. SHUMAKOV, Y. Origami Magic Ball Wonders: From dragon's egg to hot air ballon. [S.I.]: Oriland, 2001.

SPERLING, D. M. Corpo + Arte = Arquitetura: Proposições de Hélio Oiticica e Lygia Clark. Concinnitas, Rio de Janeiro, v. 1, n. 26, p. 18-35, jul. 2015. ISSN: 1981-9897.

STEWART, I. Some assembly needed. Nature, Londres, v. 448, p. 419-419, jul. 2007.

SUN, P. WANG, J. LI, X. Heat reutilizing-type clothes dryer, has protective cover layer provided with air inlet, air cylinder formed with ventilation hole, and return air channel connected with air cylinder, where rear plate is connected with air inlet. CN202744850-U, 06 jul. 2012, 20 fev. 2013.

TACHI, T. Rigid-Foldable Thick Origami. In: Origami 5: Fifth International Meeting of Origami Science, Mathematics, and Education (org. Robert Lang, Patsy W. Iverson, Mark Yim), 2010, Singapura. Encontro Internacional... Massachusetts: A K Peters, 2011. 
TEIXEIRA, S. MARAR, J. F. ROSSI, D. C. Origami contemporâneo: um estudo sobre a arte em dobra e sua mutabilidade prática. Palíndromo, Florianópolis, v. 6, n. 12, p. 94113, dez. 2014. DOI: 10.5965/2175234606112014094.

THE RON Resch Paper and Stick Film. Direção: Ronald D. Resch. [S.I.]: [s.n.], 1992. 1 vídeo online (41 min.) son., color. Disponível em: <https://vimeo.com/36122966>. Acesso em: 28 jun. 2016.

TSÉ, L. Tao-te king: O livro que revela Deus (trad. Huberto Rohden). São Paulo: Círculo do Livro, 1991.

ZIRBEL, S. A. et al. Accommodating thickness in origami-based deployable arrays. In: Proceedings of ASME 2013 International Design Engineering Technical Conferences \& Computers and Information in Engineering Conference. Conferência... Portland: The American Society of Mechanical Engineers, 2013. (37, v. 6B). ISBN: 978-0-79185594-2. 